\title{
EXPLORING THE RELATIONSHIP BETWEEN TRUCK LOAD CAPACITY AND TRAFFIC ACCIDENTS IN THE EUROPEAN UNION
}

\author{
AUTHORS \\ José I. Castillo-Manzano (jignacio@us.es). \\ Facultad de Ciencias Económicas y Empresariales, University of Seville (Spain) \\ Mercedes Castro-Nuño (mercas@us.es). \\ Facultad de Ciencias Económicas y Empresariales, University of Seville (Spain) \\ Xavier Fageda (xfageda@ub.edu). \\ Dept. of Economic Policy, University of Barcelona (Spain)
}

\begin{abstract}
Under the recent framework developed in the European Union to extend the use of higher capacity goods vehicles, this article originally analyzes how different truck configurations by load capacity, impact road safety. Through the application of econometric techniques to panel data for EU28 and controlling for explanatory variables, we find that increased truck load capacity does not necessarily get worse traffic safety. Specifically, heavy trucks do not seem to be associated with more traffic fatalities/accidents, medium trucks appear to be the worst performers for fatalities and lighter trucks the worst for accidents.
\end{abstract}

Keywords: Road freight transport, truck types, load capacity, road safety, panel data, European Union.

\section{INTRODUCTION}

Road freight traffic is a key part of the European common market. However, the external costs associated with motorized transportation have prompted the European Union (EU) to develop a more efficient, sustainable and safer transport system within a framework of liberalization and competition (e.g., Koliousis et al., 2013).

Additionally, as Sanches Rodrigues et al. (2015) explain, certain features of modern European supply chains (i.e., the high concentration of production seeking to exploit economies of scale, and large volumes of freight transported long distances across the continent) have led practitioners to call for an increase in truck dimensions. The fact 
that road freight transport seems to be a more flexible mode for door-to-door service has contributed to freight consolidation in larger and heavier vehicles (McKinnon, 2008).

However, from a road safety approach, the literature has generated unclear evidence as to the impact of large truck circulation (Carson, 2011). Therefore, the current article explores empirically how different truck configurations impact European road safety, with particular emphasis on the effect of the circulation of heavier trucks compared to other truck categories.

Authors such as Stein \& Jones (1988) consider that truck accident involvement may be affected by several factors (i.e., truck operating characteristics, such as load or size; truck driver characteristics, such as age or work conditions; weather and road conditions); while others, such as e.g., Jones et al. (1983) and Vallette et al. (1981), state that vehicle weight and loading variables are essential parameters for vehicle dynamics, roll stability and handling characteristics. Thus, we assess the safety differences between three different truck types on the basis of load capacity (i.e., light, medium and heavy trucks) in terms of traffic accidents and fatalities.

In general, the earlier literature has broadly shown that truck road accidents are a significant issue. According to Corsi et al. (2014), due to their economic and social costs, road traffic accidents involving trucks have caught the attention of governments, academicians and society in general. In recent years scientific papers have analyzed a vast array of issues. For example, Britto et al. (2010) and Cantor et al. (2008) have investigated the relationship between motor carrier safety and financial performance; Cantor et al. (2009, 2010), Hickman \& Hanowski (2011), Mejza \& Corsi (1999) and Mejza et al. (2003) have explored the effect of individual driver attributes, technologies and safety best practices on accident likelihood, while other authors have examined the impact of truck drivers' employment status (Cantor et al., 2013, and Corsi et al. 2012). Further studies have tested the influence of external factors, such as infrastructure design (Chang \& Chien, 2013); vehicle technologies and maneuvering capabilities (Mooren et al., 2014); environmental conditions (Choi et al., 2014), and specific safety policies (Castillo-Manzano et al., 2015). Some studies have even analyzed the possibility of internalizing the externalities generated by truck accidents (Anderson \& Auffhammer, 2014; Savage, 2011).

Less attention has been paid to research into the effects on traffic safety outcomes of trucks disaggregated by size, weight or configuration. Chang \& Mannering (1999) 
explain that it can be difficult to isolate the significance of these effects due to the presence of confounding factors. In addition, Carson (2011) points out that this literature represents a mixture of statistical papers and institutional reports based on different sources, models and methodologies that provide contradictory conclusions. Moreover, since the well-known TRB study (1990), most of the studies on the topic have referred to the U.S. (af Wåhlberg, 2008; Braver et al., 1997; Khorashadi et al., 2005; Welki \& Zlatoper, 2009, among many others), or discuss the safety of only one truck size category, mainly larger and heavier trucks (Anderson \& Auffhammer, 2014; Lemp et al., 2011; Zhu \& Srinivasan, 2011).

More precisely, the previous literature shows that the evidence regarding the relationships between load capacity-based truck categories and traffic accidents and their severity is fragmented or even inconclusive. In fact, the af Wåhlberg (2008) metaanalysis, possibly the broadest review published on this topic to date, states that research on this topic has been characterized by a geographic bias (most of the studies take the US as their case study) and detects certain methodological shortcomings that are basically the result of limited exposure data for holding the road type constant. Therefore, said author concludes that this issue has not been conclusively answered.

Our paper therefore attempts to shed light on this still unresolved issue by assessing the safety differences in terms of traffic accidents and fatalities between three different truck types categorized by load capacity (i.e., light, medium and heavy trucks). For this we use a comprehensive database of a large number of heterogeneous EU countries and for a broad recent timeframe, the 1999-2012 period. While the main variables of the empirical analysis are for different categories of truck load capacity, we control for several explanatory factors of safety outcomes, such as country attributes, proxies for the type of roads on which trucks circulate and specific road safety policies. We also apply country fixed effects that allow us to consider any omitted constant variable that correlates with the explanatory variables. We use different techniques (ordinary least squares and negative binomial) to verify the robustness of the results to the dependent variable being treated in different ways: as a continuous or a count variable. Note also that the estimates correct for heteroscedasticity and temporal autocorrelation in the error term. All this enables us to offer robust results on this relevant topic.

Specifically, our research aims to answer the following questions: How does truck weight - gauged by load capacity- affect European traffic safety? What differences in safety are there among different truck load capacity categories in the EU? Which truck 
load capacity category is the most hazardous for EU traffic safety? Are people more likely to be involved in fatal accidents in the EU as truck load capacity increases?

The main contribution of our investigation is that it is the first to examine EU road safety issues in relation to this specific breakdown of truck types using a broad set of control variables. We believe that our findings may serve as a starting point for the analysis of different truck types circulating on other geographic levels and in other areas; and, in a practical context, they may also be helpful to governments and policy makers by adding safety issues to the perspectives of sustainability and logistics to orient both logistics and road safety strategies. In this regard, our results could also serve as a guide to adapt technology efforts, regulation and enforcement strategies to different truck configurations.

The timeliness of our research is justified by recent EU and individual government initiatives to extend the use of higher capacity freight vehicles. The body of EU legislation that addresses standard regulations on maximum weights and dimensions for heavy goods vehicles, buses and coaches is mainly molded by Directive 96/53/EC. This norm ensures the unhindered circulation of vehicles within these limits in Member States ${ }^{1}$. It also places restrictions on the cross-border circulation of vehicles that are heavier, longer or higher than these standards, the so-called Mega Trucks, Longer and Heavier Vehicles (LHVs), and EuroCombis or Gigaliners ${ }^{2}$. The European Commission (EC) has attempted to legalize the cross-border circulation of mega trucks during recent years, but the initial Directive has recently been amended by Directive (EU) 2015/719, which provides for derogations from the maximum lengths to improve the safety and environmental emissions of heavy goods vehicles (through improved aerodynamic performance) and also recommends that no modifications should be made to Directive 96/53/EC's restrictions on the cross-border movement of mega trucks ${ }^{3}$.

\footnotetext{
${ }^{1}$ Today different EU countries have different national regulations regarding maximum dimensions. According to this Directive, the maximum permitted length is 16.50 meters for semitrailers and 18.75 meters for road trains with a total combined weight of 40 tonnes (the so-called Heavy Goods Vehicles, HGVs).

${ }^{2}$ Up to 25 meters in length and 60 tonnes in weight.

${ }^{3}$ These vehicles are already circulating in some Scandinavian countries with less advanced rail systems (Sweden and Finland), and other States have carried out pilot tests (the Netherlands, Germany, Denmark, Belgium). Mega truck or LHV cross-border traffic is a controversial issue in the EU due to a conflict of interests between the haulage industry, governments, institutions and public opinion (with a powerful campaign opposing mega trucks on the www.nomegatrucks.eu website, with opposition from 243 organizations in 24 countries. Even the European Parliament has shown its reluctance). For a detailed analysis on the impact of mega trucks see Ortega et al. (2014) and Steer et al. (2013), among others.
} 
Following this introduction, the remainder of the paper is organized as follows: Section 2 presents the theoretical background to our analysis and the research hypotheses; Section 3 describes the data, the variables and the model used; Section 4 analyzes and discusses the results, and Section 5 summarizes the main conclusions and implications for policy.

\section{THEORETICAL BACKGROUND AND HYPOTHESES.}

Most of literature on the topic agrees that differences in truck weight affect road safety since, from a technical point of view, they lead to different designs, configurations and driving performance. Consequently, as truck traffic tends to change, there are also changes in risk exposure to accidents. A number of scholars, such as Abdel-Aty \& Abdelwahab (2004), Bálint et al. (2013), Cantor et al. (2010), Carson (2011), Corsi et al. (2012, 2014), Dong et al. (2014) and Khorashadi et al. (2005), among others, have demonstrated this using a variety of approaches. Given that each truck configuration has its own specific problems, Kahane (2003) highlights physics and intuitive reasons (mass differences, speed differences and a range of other safety factors) that may explain why different weights can be expected to present different accident risks.

Nevertheless, from studies such as Braver et al. (1997) that do not find any relevant truck safety differences linked to weight in fatal accidents, the meta-analysis by af Wåhlberg (2008) (possibly the most comprehensive quantitative review published on the topic to date) deduces that this question has not been conclusively answered, as the relationship between truck weight and road safety is really a nonlinear correlation dependent upon the accident category considered.

We take as our starting point this relevant contribution by af Wåhlberg (2008), whose outcomes point to accident risk increasing in line with increasing truck weight up to a certain point, except in the case of fatal accidents. However, the author indicates that this finding may only be valid for North America and notes that there are several methodological issues with studies, mainly due to limited exposure data for holding the road type constant. 
Further analysis of the literature on safety differences among the different truck categories could help to reveal the sign of this relationship.

A priori, the association between heavy trucks and road safety outcomes (re: light trucks) seems to be a complex issue because, as Milton et al. (2008) argue, there are two forces depending on the accident category. On the one hand, a higher number of heavy trucks can lead to a decrease in accident risk due to a variety of factors. For example, heavy trucks are mainly used for inter-urban trips (Kanaroglou \& Buliung, 2008) and as af Wåhlberg (2008) highlights may have an advantage from circulating on better and safer roads (highways). Moreover, according to Cantor et al. (2008, 2009), Corsi et al. (2012, 2014), Huang et al. (2008) and Welki \& Zlatoper (2009), the implementation of the latest safety technologies, specific safety regulations and performance measures for heavy vehicles means that they are more resistant, due to their superior dynamic stability and control. In addition, as Lemp et al. (2011) state, one heavy truck may replace several light trucks, meaning that if heavy trucks are used, fewer truck trips are required to haul any given volume of freight (lower risk exposure). Lastly, as Milton et al. (2008) argue, the presence of heavy trucks may have a slowing effect on traffic speed.

On the other hand, although their occupants may be better protected, heavy trucks may also be involved in more severe accidents than light trucks, mainly due to more dangerous maneuvers and as they are less flexible, because of the weight and speed differential (Carsten, 1987; Chang \& Chien, 2013; Dong et al., 2014; Khorashadi et al. 2005; Qin et al., 2013, and Zhu \& Srinivasan, 2011).

Accidents specifically involving light trucks have been also explored, although the findings have also differed depending on the road safety outcome considered. The accident risk of light trucks seems to be higher than that of heavy trucks, especially in urban settings. According to Kanaroglou \& Buliung (2008) the reason for this is that freight distribution mostly requires goods to be transported over short distances by light trucks, especially in the case of the major medium and large European cities where, as Dablanc et al. (2013) state, typical urban morphologies (high traffic density, parking problems, commercial-leisure-tourist activities concentrated in the city center) influence mobility and restrict the circulation of heavier goods vehicles for freight pick-up and delivery. Friswell \& Williamson (2010) state in this regard that the urban environment 
creates more hazardous exposure for light truck drivers because of the stress that comes from heavy traffic or a lack of parking space. On the other hand, specific light truck features (e.g., a high center of gravity that may increase the risk of rollover, a stiffer structure and worse maneuverability, Anderson, 2008) may also drive up accident risk. Abdelwahab \& Abdel-Aty (2004), Abdel-Aty \& Abdelwahab (2004), Harb et al. (2007) and White (2004) provide evidence of a greater likelihood of rear-end and multivehicle collisions in urban settings involving light trucks because they impede drivers' visibility of other smaller vehicles (passenger cars, bicycles, motorcycles) and pedestrians. Also, Desapriya et al., (2010) suggest that light trucks pose a greater risk of pedestrian injuries and deaths.

Other studies analyze factors that also contribute to higher accident risk for light trucks compared to heavy trucks. For example, the number of light trucks has grown considerably in recent years (Welki \& Zlatoper, 2009). Certain authors even conclude that the behavior and qualification levels of drivers in these two truck categories are different. For example, a comparison by Huang et al. (2011) finds that heavy truck drivers (with more stringent requirements to obtain the corresponding driving license) are more frequently commercial drivers who are supposed to be better qualified to respond in hazardous situations. Using a Florida accident database the same study also detects that light truck drivers are more aggressive behind the wheel.

In sum, the evidence of the net effect of light trucks on traffic fatalities seems to be ambiguous. Depending on the methodological design, we find studies that only focus on the fact that in a fatal collision the greater mass of a light truck may provide better protection for its occupants compared to smaller vehicles, e.g., cars (Evans \& Frick, 1993, 1994; Gayer, 2004; Ossiander et al., 2014). However, there are also a number of studies such as Brozović \& Ando (2009), Gayer (2004) and White (2004) that attempt to split the net fatality effect of light trucks into its internal and external impacts (i.e., also considering the externalities for other road users). Using an alternative approach based on the combination of both accident-level data and U.S. state-level data, Anderson (2008) indicates that because of their greater mass and specific features, light trucks may generate an external safety cost to the occupants of other vehicles that could neutralize the initial safety advantage for their own occupants. 
In short, taking into account all the above evidence (mostly for the U.S. case), we formulate Hypotheses 1 and 2:

\section{Hypothesis 1 (H1): Heavy trucks are linked to fewer traffic accidents than light trucks.}

\section{Hypothesis 2 (H2): Heavy trucks are linked to more traffic fatalities than light trucks.}

Returning to the literature that analyzes the impact of heavy trucks on safety, we note that a number of studies, almost entirely for the U.S. case, consider a broad category for this truck type called "large trucks", i.e., vehicles with gross vehicle weight in excess of 10,000 pounds: e.g. among many others, Blower et al. (2010) for mechanical conditions and crash involvement; Hauer (2001), measuring the safety of certain vehicle type driver groups; Lyman \& Braver (2003), considering occupant deaths, and Zaloshnja \& Miller (2004) calculating the cost of crashes.

However, as Park \& Pierce (2013) state, considering a separate specific medium trucks category (for example, for trucks between 10,001 and 26,000 pounds) would improve knowledge of truck safety. The research that considers a separate category of medium size trucks in road safety is quite scarce. Nevertheless, in general terms the few studies that follow this disaggregation agree that, compared to heavy trucks, there are differential operational characteristics and accident environments for medium trucks that lead to both a higher risk of accidents and more severe accidents: e.g., higher speeds with more severe results in the case of an accident, more aggressive driving, and drivers who are often not required to possess a commercial driver's license. These studies are for the U.S. (Huang et al., 2011; Park \& Pierce, 2013; Pierce \& Park, 2014) and for Sweden (Bálint et al., 2013) respectively, but they only evaluate truck types in terms of length and do not take into account other aspects, such as load capacity. However, there is one study of the U.S. (Corsi et al., 2014) that explains how and why vehicles in a truck category equivalent to our study's medium trucks (10,001-26,000 pounds) present worse driver performance and higher traffic violation rates than heavy trucks.

Consequently, the previous research and logic lead us to expect that medium trucks might possess a mix of the characteristics of both heavy and light trucks - for example, 
they can be used for both urban and inter-urban journeys- as a result of which medium trucks might also possess a combination of safety risks. Thus, we formulate the following Hypotheses, $\mathrm{H} 3$ and $\mathrm{H} 4$ :

Hypothesis 3 (H3): Heavy trucks are linked to fewer traffic accidents than medium trucks.

Hypothesis 4 (H4): Heavy trucks are linked to fewer traffic fatalities than medium trucks.

Our Hypotheses model can be represented by Figure 1 .
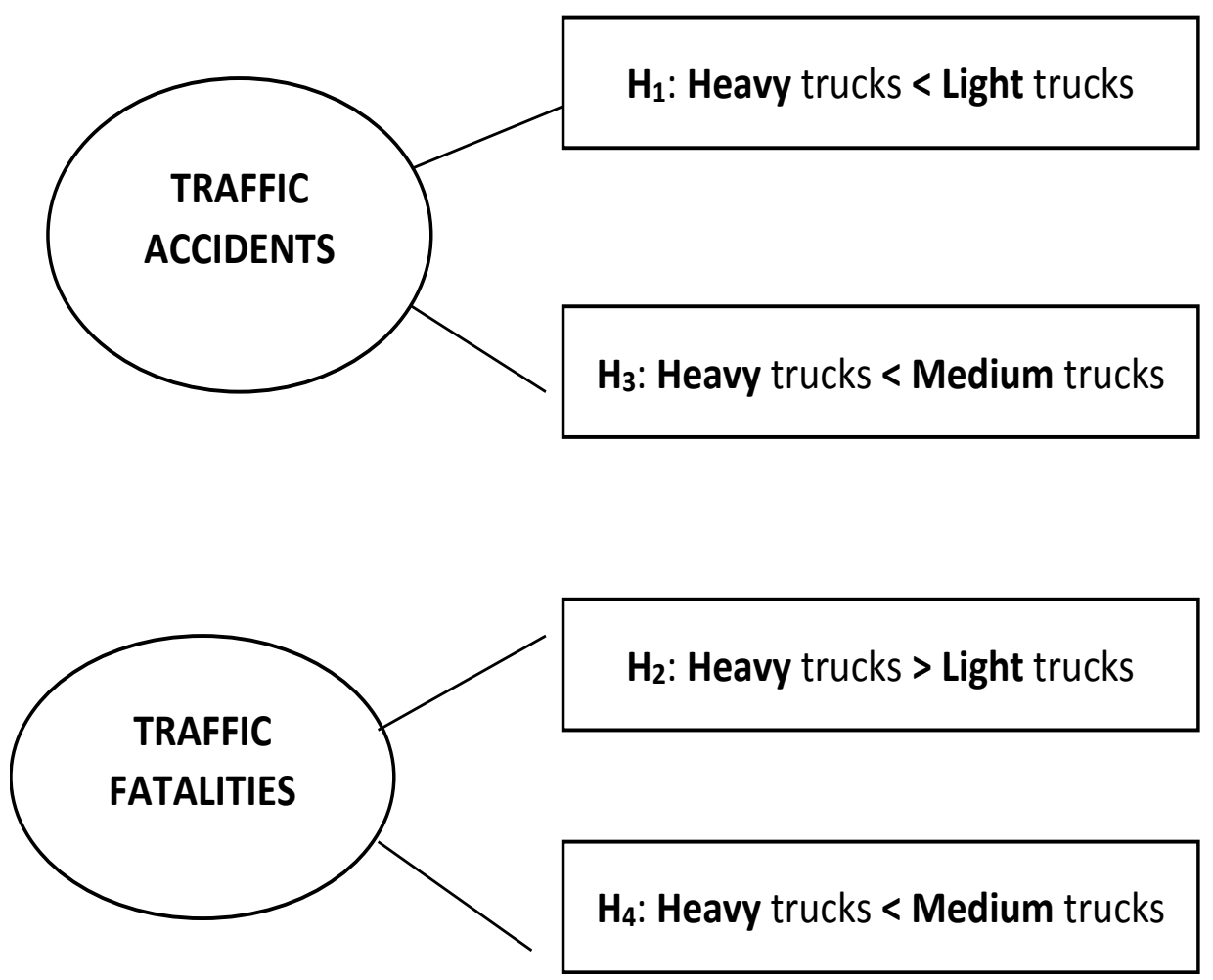

Figure 1: Conceptual model.

Source: Authors.

\section{EMPIRICAL FRAMEWORK}

We estimate a model that takes the following form for country $i$ during period $t$ : 


$$
\mathrm{Y}_{\mathrm{it}}=\alpha+\beta_{\mathrm{k}} \mathrm{X}_{\mathrm{it}}+\gamma_{\mathrm{k}} \mathrm{Z}_{\mathrm{it}}+\lambda_{\mathrm{k}} \mathrm{W}_{\mathrm{it}}+\mu_{\mathrm{i}}+v \mathrm{Year}_{\mathrm{t}}+\varepsilon_{\mathrm{it}}
$$

in which we consider two different $\mathrm{Y}_{\text {it }}$ dependent variables estimated in two different regressions. First, we consider the log of the total per capita fatality rate (within 30 days of the accident, according to the Vienna Convention definition) as the dependent variable $^{4}$. Second, we consider the $\log$ of the total accident rate as the dependent variable.

$\mathrm{X}_{\mathrm{it}}$ contains the vector of the country's economic and demographic attributes; $\mathrm{Z}_{\mathrm{it}}$ refers to truck-related variables, and $\mathrm{W}_{\text {it }}$ represent road safety policy-related variables. $\mu_{\mathrm{i}}$ are country fixed effects that control for omitted time-invariant country-specific variables; Year is an annual time trend that controls for the common trend in all the countries in the dataset, and $\varepsilon_{i t}$ is a mean-zero random error. Note here that the only data available are annual and aggregated at the country level. This results in some limitations, as we cannot control for seasonal effects or regional differences.

We use data for the EU28 countries from 1999 to 2012 and the unit of observation is the country-year pair: 1999 is a relevant year for our scope, as it is the year that the socalled 'Eurovignette' Directive 1999/62/EC (modified by Directive 2006/38/EC and Directive 2011/76/EU) was passed that aimed to harmonize the tolls and vignettes associated with the cost of road infrastructure in Member States and charge them to Heavy Goods Vehicles. 2012 is the most recent year for which data were available for the majority of the countries considered.

However, data for truck-related variables were not available for some countries (Belgium, Bulgaria, Greece and the United Kingdom) and so these countries were excluded from the econometric analysis. Data were available for Austria, Croatia, Cyprus, the Czech Republic, Denmark (1999-2002), Estonia (2007-2012), Finland, France (2010-2012), Germany (1999-2008), Hungary (1999-2008, 2010), Ireland (1999), Italy (2004-2012), Latvia, Lithuania (all years except 2008), Luxembourg (1999-2009), Malta (all years except 2003-2007), the Netherlands (all years except 2012), Poland (2002-2012), Portugal (2011-2012), Romania (2008-2012), Slovenia (all years except 2003-2004), Spain (2005-2012) and Sweden (all years except 2010 and 2012).

\footnotetext{
${ }^{4}$ This is the dependent variable typically used to assess road safety outcomes, as the interpretation of policy variables is clearer.
} 
With respect to the countries for which data were not available for all years, we include data for the years for which we do have information, as is generally done in unbalanced panel data regressions. Note here that data for truck variables account for 231 observations and data for other variables, such as fatalities and accidents, are also incomplete. Thus, for some country-pairs we may have information for truck variables but not, for example, for fatalities. Hence, the final sample comprises 222 observations. Note here that any regressions with only one observation for a country fixed effect (as is the case for Ireland, for example) automatically exclude said observation.

Tables 1 and 2 give the descriptions, information sources, descriptive statistics and number of observations available for all of the variables used in the analysis. We also specify the variables that capture country attributes, truck numbers and specific safety policy variables. All the variables present adequate variability, given that standard deviation is relatively high in relation to mean values. However, the variability of some variables, such as motorway density, may be low over time.

\section{[INSERT TABLE 1]}

\section{[INSERT TABLE 2]}

As explanatory variables we include the per capita gross domestic product (GDP) as an indicator of the country's economic development (Castillo-Manzano et al., 2013, 2014; Grimm \& Treibich, 2013; Yannis et al., 2014). The relationship between a country's economic development and road safety outcomes could be expected to be an inverted U-shape (Bishai et al., 2006; Kopits \& Cropper, 2005; Loeb \& Clarke, 2007). Indeed, fatality and accident rates may increase with economic development in very poor countries, due to increased exposure to road traffic accidents. However, the relationship between economic development and traffic safety outcomes may become flat or even invert after reaching a certain wealth threshold. We test the hypothesis concerning non-linearity between GDP and traffic safety outcomes by including the GDP and the square of the GDP as explanatory variables. If the non-linear relationship is confirmed, then the coefficient for the GDP variable will be positive and the coefficient for the $\mathrm{GDP}^{2}$ variable will be negative.

The number of passenger cars per capita (motorization) is also taken into account. This variable relates to the level of development of private transportation. Regarding the expected sign of this coefficient, on the one hand, higher motorization rates may imply higher exposure to road traffic accidents, while on the other, more developed countries 
may have better infrastructure and vehicles, more advanced policies and more beneficial social attitudes towards road safety (Kopits \& Cropper, 2005). By way of example, Albalate \& Bel (2012) found a negative relationship between traffic fatalities and the motorization rate.

We also take into account the influence of the quality of transport infrastructure by including a variable for motorway density. The sign of the coefficient for this variable is expected to be negative. Indeed, a negative relationship can be expected between the quality of transport infrastructure and road safety outcomes, as was found in Jamroz (2012) and Noland (2003). It should be noted that Malta and Latvia do not possess any motorways, which explains why the sample includes countries with zero motorway density.

We also include the density of other roads (state, provincial and district roads) as an explanatory variable. This variable could capture the influence of inter-urban trips on lower quality roads or more frequent short trips. Hence, a priori the sign expected for this variable is not clear in either the traffic fatalities or accidents equations. By including this variable, we seek to take into account the methodological indications in the relevant meta-analysis by af Wåhlberg (2008). Said author identifies the lack of appropriate exposure data regarding road type as the main problem in studies that analyze the safety impact of different truck configurations. Larger trucks usually circulate on larger, safer roads (highways), which could represent a certain advantage and possibly skew the comparison of the findings for different truck configurations.

We also consider two control variables for the percentage of vulnerable population in each country. First, we include a variable for the percentage of the population over 60 years old. Second, we also consider a variable for the percentage of the population aged 15-24 years. While we may expect that risk exposure is higher for the younger population, since younger road users usually take more risks (Langford et al., 2006), the impact of accidents may be greater for senior road users, and so morbidity and mortality rates may be higher for older populations (Braver \& Trempel, 2004; Yee et al., 2006). Thus, we expect positive signs in the traffic fatalities equation for the coefficients for these two explanatory variables, while a negative sign is expected in the accidents equation for the old population coefficient and a positive sign for the young population coefficient.

Additionally, we include a variable for the population density of the country. We may expect that the proportion of urban trips (short distance trips in intra-urban 
neighborhoods; Holz-Rau et al., 2014) over total trips will be higher in more densely populated countries; and specifically, following Allen et al. (2012), trips for urban freight activities are associated with city population density. The accident rate should be higher for intra-urban trips than inter-urban or rural trips, but the severity of accidents may be lower for intra-urban trips, due, according to Rakauskas et al. (2009) and Zwerling et al. (2005) among others, to factors such as road design, emergency medical service proximity and lower differential speeds. Hence, the coefficient for this variable is expected to have a positive sign in the accidents equation, while a negative sign might be found in the traffic fatalities equation.

We also include additional variables for road safety policies. Following previous studies on road safety (Albalate, 2008; Castillo-Manzano \& Castro-Nuño, 2012; Castillo-Manzano et al., 2013, 2014), we consider the influence of prevention policies such as legal blood alcohol limits. A dummy variable is included with a value of one for countries and periods where the maximum blood alcohol concentration allowed for professional drivers is under $0.5 \mathrm{~g} / \mathrm{L}$. Most EU28 countries have set the limit at 0.5 or below, so we are able to test whether blood alcohol concentration rates of under 0.5 for professional drivers are effective for improving road safety outcomes.

Moreover, we add a variable that captures the implementation of points-based driving licenses through a dummy variable with a value of one if a penalty driving license system is applied. The introduction and application of any type of points system to driving licenses may lead to lower traffic fatality and accident rates, although the long-term effect of this policy has been questioned (see Castillo-Manzano \& CastroNuño, 2012, for an international meta-analysis of the effects of this type of policy).

Another road traffic policy variable that we take into account is the maximum speed limit on motorways. According to previous studies (Elvik, 2012), a positive sign may be expected for the coefficient for this variable, as one of the consequences of a higher speed limit may be a higher number of road traffic fatalities and accidents.

The most relevant variables in our analysis relate to truck load capacity ${ }^{5}$. We therefore include three variables for the number of trucks per capita ${ }^{6}$ that consider three

\footnotetext{
${ }^{5}$ Overall, we may expect a stronger (negative) impact of trucks on traffic fatality than passenger cars. Castillo-Manzano et al. (2015) examine the differential impact between the motorization rates for trucks and passenger cars but do not distinguish between different truck categories, which are essential for our analysis.

${ }^{6}$ Motorization variables (both for passenger cars and trucks) are in per capita terms, as this is a common indicator in international statistics and the road safety literature. It might be interesting to test our model with an alternative indicator of motorization, such as the ratios between numbers of passenger
} 
load capacity categories. We opt for this variable for truck types because, following the ITF (2010), load volume determines the number of trucks required per unit of freight, and a higher load capacity can result in fewer vehicle-kilometers traveled.

For the U.S. case study, and following both the Federal Highway Administration (FHWA) and the National Highway Traffic Safety Administration (NHTSA), most papers on the topic classify trucks in three groups by Gross Vehicle Weight (GVW) expressed in pounds. However, there are no equivalents to these groups in terms of load capacity in any official statistics available in Europe. Thus, our research is based on the following categories in line with data provided by Eurostat:

1) trucks with a load capacity of under $5000 \mathrm{~kg}$,

2) trucks with a load capacity of between $5000 \mathrm{~kg}$ and $14999 \mathrm{~kg}$, and

3) trucks with a load capacity of $15000 \mathrm{~kg}$ or over.

As was to be expected, the mean value data in Table 2 show that light trucks are much more numerous than trucks in the other categories. In contrast, the numbers of trucks in the other two categories are quite similar.

We would like to state that the variables used in the empirical analysis are not proxies for country size. Variables are measured in per capita terms (fatalities, GDP, motorization, truck load capacity variables, population and motorway density - the latter two in per km terms) and are not linked to country size (road safety policy variables, percentage of vulnerable population).

\section{RESULTS AND DISCUSSION}

Table 3 shows the correlation matrix of the variables used in the empirical analysis. Some variables are highly correlated, particularly the GDP per capita and motorization variables. These high correlations may cause a multicollinearity issue. Multi-collinearity can exaggerate estimates of the parameter variance and distort its statistical significance or even result in parameter estimates of implausible magnitude in the most extreme cases.

[INSERT TABLE 3]

cars and trucks and total road-kilometers. Unfortunately, Eurostat data for the number of road-kms are very poor and are not available for several countries. Reported data show significant differences among countries (taking load capacities into account) and significant changes within some countries in just one year. 
The Variance Inflation Factor (VIF) is a measure that is widely used to examine the degree of multicollinearity between explanatory variables. Several rules of thumb for VIF have been considered as a sign of severe multicollinearity. The usual rule of thumb considered in the econometric textbooks is 10 , although practitioners may use lower threshold values and a value of 5 is common.

Table 4 shows the variance inflation factors of all the variables used in the empirical analysis. The computed VIFs are below 5 for the majority of the variables and below 10 for all of the variables. It is important to note that the truck motorization variables do not seem to be affected by any multicollinearity issues in our research.

\section{[INSERT TABLE 4]}

Estimates may present problems of heteroscedasticity and temporal autocorrelation in the error term. Running the Wooldridge test for autocorrelation in panel data shows that there may be a problem of serial autocorrelation that needs to be addressed. Additionally, the Breusch-Pagan/Cook-Weisberg test indicates that we have an issue with heteroscedasticity. We also apply the panel unit root test developed by Levin et al. (2002), which can be regarded as an augmented Dickey-Fuller (ADF) test when lags are included. This test indicates that there is no non-stationarity problem with our dependent variable. We also apply the Ramsey Reset Test, which confirms that no relevant variables have been omitted from our model. The results of these tests are given in Tables 5 and 7.

Taking the results of these tests into account, we performed the estimation using two different techniques to check for robustness. In Table 5 we report the results of the traffic fatality regressions using the ordinary least squares (OLS) method with country fixed effects. The standard errors are robust to heteroscedasticity and clustered by country to address the autocorrelation problem. In Table 6 we report the results of the traffic fatalities equations using the population-averaged panel-data model with a negative binomial distribution. The standard errors are robust to heteroscedasticity, as they are in the OLS regression. An advantage of these latter regressions is that we can specify an AR(1) within-group correlation structure for panels. Population is used as an exposure variable. In Table 7 we show the results of the accidents equation using both techniques. 
It should be noted that the negative binomial distribution explicitly models the dependent variable as the number of occurrences. The dependent variable in the OLS regression is total fatalities or accidents per capita, while in the regression that uses the negative binomial distribution the dependent variable is total fatalities or total accidents, with population as an exposure variable.

In Tables 5 and 6 we report the results of four different specifications of the road traffic fatalities equation, while Table 7 shows the results for the accidents equation. We report the results of different specifications. Specification (1) is the baseline regression. Specification (2) adds the lagged value of the dependent variable as an explanatory variable to check whether results with a dynamic estimator differ from the baseline model. Specifications (3) and (4) add two different interaction variables (centering the variables to prevent any multicollinearity issues): interaction between GDP per capita and motorization rate, since the effects of the motorization rate on road safety outcomes may vary depending on GDP per capita; and interaction between trucks per capita and the motorization rate, since mixing higher levels of car and truck traffic may lead to worse safety outcomes. For the sake of simplicity, we do not report the results of specification (3) for the accidents equation, as the interaction variables are not statistically significant when the dependent variable is the accident rate.

As the reported $\mathrm{R}^{2}$ in the OLS regression shows, the overall explanatory power of the regressions is very high. However, several explanatory variables are not statistically significant and the country fixed effects may capture the effect of several explanatory variables with little variability over time.

Regardless of the estimation technique used, we find evidence of a non-linear relationship between the road traffic fatality rate and a country's level of economic development, as was found in Bishai et al. (2006), Kopits \& Cropper (2005) and Loeb \& Clarke (2007). Indeed, the coefficient for the GDP variable is positive and statistically significant, while the square of the same variable is negative and statistically significant. In contrast, the GDP per capita variable does not seem to be consistently relevant in the accidents equation. In the accidents equation, the inverse Urelationship between GDP and accidents is only found in the OLS regressions that do not include the lag of the dependent variable as the explanatory factor.

The number of passenger cars per capita motorization rate variable is generally not statistically significant in either the traffic fatalities or the accidents equation. In the traffic fatalities equation, the interaction between motorization and the GDP per capita 
variable is positive and statistically significant. This provides some evidence that the effects of motorization on road traffic fatalities may vary according to GDP per capita. Furthermore, the interaction between trucks per capita and the motorization rate variable is statistically significant whichever technique is used. In contrast, the correlation between the interaction variable and the truck load capacity variables may be distorting the individual identification of the above-mentioned variable.

The motorway density variable is not significant regardless of the dependent variable and estimation technique used. The variability of this variable over time is low, meaning that the country fixed effects model may already be capturing its effect. In contrast, the road density variable is positive and statistically significant in all the regressions that use traffic fatalities as the dependent variable, although it is not statistically significant when the dependent variable is the accident rate. Hence, this variable seems to capture the effect of inter-urban trips with lower quality infrastructure.

The younger population variable is positive and statistically significant in most of the traffic fatalities equation regressions and in all of the accidents equation regressions. This confirms that younger people are subject to higher risk exposure. In contrast, the older population variable is positive but generally not statistically significant in the traffic fatalities equation and negative and generally statistically significant in the road accidents equation. This result confirms that the elderly incur less risk than other age groups, although this may not have a strong effect on the fatalities outcome.

The population density variable is negative and statistically significant in all of the fatalities equation regressions, and is positive and statistically significant in all of the accidents equation regressions. As mentioned above, the proportion of urban trips may be higher in more densely populated countries. Hence, the results for this variable suggest that accidents strongly correlate with urban trips, but that the accidents for these urban trips are not as severe.

Regardless of the technique used, we find that speed limits are effective for reducing road traffic fatalities and accidents (in line with previous research, such as Saifizul et al., 2011) while points-based driving license systems are less effective (in accordance with the findings of a worldwide meta-analysis by Castillo-Manzano \& Castro-Nuño, 2012). Contrary to our expectations, we do not find that legal blood alcohol limits have a significant effect.

The time trend is negative and statistically significant in the traffic fatalities equation, whichever estimation technique is used. This is proof of a systematic reduction in road 
traffic fatalities over time. The results for this variable are less clear in the accidents equation, as the sign and statistical significance vary in the different regressions reported in Table 7.

Regarding our main explanatory variables for truck load capacity, if we consider the overall results we obtain different statistical significance and signs for the three categories of trucks and for each traffic safety outcome (accidents per capita and fatalities per capita).

First, we find that the coefficient for the heavy trucks variable is generally not statistically significant in the regressions that take traffic fatalities as the dependent variable. However, the coefficient for the heavy trucks variable is negative and generally significant (at the 10\% level) in the regressions that take accidents as the dependent variable. We therefore deduce that accident risk does not necessarily increase with a rise in the load capacity of trucks circulating on EU, although this finding is not significant for fatal accidents.

Lower accident risk for heavy trucks may be supported by a combination of explanations provided by scholars such as: Lemp et al. (2011), who point to larger trucks resulting in fewer truck trips; Milton et al. (2008) who state that the presence of heavier trucks on roads may have a slowing effect on average traffic speed; and others, such as Cantor et al. (2009, 2010), Carson (2011), Corsi et al. (2012), Mejza et al. (2003) and Mooren et al. (2014), who consider other factors. For instance, larger motor carriers are subject to stricter regulatory systems to promote safer and more efficient vehicles; they are leaders in the implementation of safety technologies and performance measures for improving dynamic stability and preventing collisions with vulnerable road users ${ }^{7}$, and they have more experienced and qualified drivers with stable and secure employment.

The non significant coefficient obtained for traffic fatalities is a more complex issue. Unlike most prior studies we have included control variables for different road types to take into account the fact that heavier trucks tend to circulate on better and safer roads. Nevertheless, our unprecedented broad panel data for $28 \mathrm{EU}$ countries do not allow us to collect available data to consider other variables that, according to the relevant metaaf Wåhlberg (2008) analysis, might explore this result further (e.g., differences in age

\footnotetext{
${ }^{7}$ See, for example, additional safety equipment proposed in London to avoid heavy truck accidents involving pedestrians and cyclists: https://consultations.tfl.gov.uk/buses/safer-lorries.
} 
and experience of drivers of different trucks; drivers that adapt their behavior to heavy truck safety problems).

Second, the coefficient for the light trucks variable is positive and statistically significant in all of the accidents equation regressions, but it is not statistically significant in the traffic fatalities equation. Therefore, in line with prior studies for the American case, higher numbers of light trucks circulating on EU roads leads to greater accident risk but not necessarily to more severe accidents. According to Abdelwahab \& Abdel-Aty (2004), Abdel-Aty \& Abdelwahab (2004), Anderson (2008), Harb et al. (2007) and White (2004), among others, specific features of light trucks and greater risk exposure, generally in (more hazardous) urban settings, might explain this effect, although with ambiguous net impacts in terms of fatality risk.

In Tables 5 and 6 we report the results of a test for any differences in the light truck and heavy truck coefficients when the dependent variable is fatalities per capita. Broadly speaking the test results suggest that the coefficients are indeed different, bearing in mind that the coefficient for heavy trucks is smaller than for light trucks. Thus, our results clearly suggest that light trucks cause more traffic accidents than heavy trucks. However, as the coefficients are not statistically significant the evidence that we find for heavy trucks having a lesser impact on traffic fatalities than light trucks is weak.

Consequently, the above findings enable us to confirm Hypothesis H1 while Hypothesis $\mathbf{H} \mathbf{2}$ is not confirmed.

Third, we also find that medium trucks increase the number of traffic fatalities, as the medium trucks variable is positive and statistically significant in all of the traffic fatalities equation regressions.

The European Accident Research and Safety Report (by Volvo Trucks, 2013) provides evidence of different heavy and medium truck patterns, which might explain this: accidents involving unprotected road users or involving other vehicles are more common for medium trucks. It should also be noted that the higher mass of medium trucks compared to smaller vehicles may mean that they are less flexible and have more complex dynamics than light trucks, while due to their lower weight compared to heavier vehicles, they may also be faster than heavy trucks. Regarding the drivers of medium trucks, Corsi et al. (2014) show that driving performance is worse and traffic violation rates are higher for medium trucks than heavy trucks in the U.S. 
To provide additional proof of the strength of the medium trucks variable we implement two different tests to show the unique explanatory power of this independent variable when it is added to the model. More specifically, we apply two different tests for nested models. The F-test for the null hypothesis that the variable omitted from the restricted model -the number of medium trucks- equals zero takes a value of 15.62 and is statistically significant at the $1 \%$ level. Furthermore, the likelihood-ratio test of the null hypothesis that the variable omitted from the restricted model -the number of medium trucks- equals zero takes a value 23.06 and is also statistically significant at the $1 \%$ level. Thus, both tests confirm the strength of the variable being considered.

Note here that in Table 7 we report the results of a test for the difference between medium truck and heavy truck coefficients when the dependent variable is accidents per capita. The results of the test confirm the differences in the coefficients when using the negative binomial distribution (which is our preferred estimation technique) but not when using an OLS regression. Thus, our results clearly suggest that medium trucks result in more traffic fatalities than heavy trucks. Furthermore, we find some evidence for the hypothesis that heavy trucks are involved in fewer accidents than medium trucks.

Therefore, these results confirm Hypothesis $\mathbf{H 4}$, while we find some evidence in favor of Hypothesis H3.

In general, not only statistical significance needs to be examined, but also the elasticities obtained from the estimated coefficients (evaluated at the sample means). Regarding the OLS regressions, a 10 percent increase in the number of medium trucks leads to an approximately 1.5 percent increase in the number of road traffic fatalities, while the increase is approximately 0.9 percent for light trucks. Additionally, a 10 percent increase in the number of heavy trucks leads to an approximately 0.5 percent decrease in the number of road traffic fatalities. Regarding the regressions with a negative binomial distribution, there is an approximately 1.2 percent increase in the number of road traffic fatalities for medium trucks and an approximately 0.4 percent increase for light trucks. The elasticities for the heavy truck variable imply that a 10 percent increase in the number of heavy trucks leads to an approximately 0.3 percent reduction in the number of road traffic fatalities.

Regarding accidents, elasticities obtained from the coefficient estimates are similar whichever estimation technique is used. Thus a 10 percent increase in the number of light trucks leads to an increase in the number of accidents of about 11 percent. 
Furthermore, a 10 percent increase in the number of medium trucks leads to an approximately 0.2 percent decrease in road accidents. Finally, the elasticities for the heavy truck variable imply that a 10 percent increase in the number of heavy trucks leads to a reduction in the number of road accidents of approximately 4 percent.

In summary, our analysis suggests that from a safety perspective it may be optimal to implement policy measures to reduce the number of medium trucks (which are the trucks that lead to higher traffic fatalities) and encourage a switch to heavy trucks. According to our results, this may improve road safety outcomes.

\section{CONCLUDING REMARKS}

The aim of the current paper was to explore the different impacts of three truck configurations based on truck load capacity (i.e., heavy, medium and light trucks) on road safety outcomes (i.e., accidents and fatalities) using European panel data. This is the first study to examine truck road safety with this breakdown of truck types, and the first to examine this breakdown in the European Union (EU). Compared to earlier research, mostly skewed towards the U.S. case and with certain methodological inconsistencies that come from exposure data for different types of roads not being adequately considered, our study provides robust estimates that aim to fill these gaps. Specifically, our study applies different econometric techniques in the panel data framework to address the relationship between truck groups classified by load capacity and different accident categories for a broad geographical study case (several EU Member States), considering a variety of control variables, such as proxies for the types of road and for a wide timeframe.

Our results enable us to answer the research questions initially posed in the article. Differences in truck load capacity seem to influence road safety in the EU, but this influence is non-linear and depends on the accident type. Medium trucks are the worst performers in terms of traffic fatalities, while light trucks are the worst performers in terms of traffic accidents. Overall, heavy trucks do not seem to be associated with either more accidents or more fatalities. 
Medium trucks may be less flexible than light trucks and can reach higher speeds than heavy trucks. Additionally, light trucks may be more frequently used for urban trips and are associated with greater risk exposure to traffic accidents.

Heavy trucks may be more resistant to accidents and are leading adopters of safety equipment. They also usually circulate on wider, better and safer roads and are subject to stricter speed limits due to their weight and size. Furthermore, they could replace a greater number of light or medium trucks, thus reducing vehicle-kilometers traveled and improving road safety per unit of freight moved.

In summary, as the correlation between economic activity and road safety is not linear but an inverse U-shaped curve, our findings seem to point to the existence of a complex relationship between trucks categorized by load capacity and road safety. We find a negative linear relationship between accidents and truck load capacity, where the highest number of accidents can be observed for light trucks. In the case of the most severe accidents (with fatalities), this relationship can resemble an inverse U-shaped curve, where the maximum of the curve can be observed for medium trucks: whereas the af Wåhlberg (2008) meta-analysis pointed to the existence of a positive non-linear relationship between the accident rate and truck load capacity, our estimations further clarify the relationship.

This reinforces the general idea that an apparently complicated correlation exists between variables to explain road accidents and their severity that goes beyond simple linear relationships. Further research is clearly needed into this issue, especially in other geographical areas outside the EU, to test the validity of this inverse U-shaped curve between trucks categorized by load capacity and traffic fatalities.

From practical and policy perspectives, our results show that heavy trucks might be safer than light trucks. This may provide a basis for improving engineering designs, managing more innovative systems and adopting customized regulatory frameworks for different truck weights and configurations in the EU. This is in line with e.g., the Corsi et al. (2014) study, which recommends the adoption of stricter vehicle inspections and enforcement for medium trucks in the U.S.

Heavy trucks may therefore improve road safety and the logistics sector may benefit from increased efficiency and productivity due to their exploitation of scale economies, as higher capacity trucks carry more freight in fewer vehicles and may also offer benefits in the form of less traffic congestion and fewer emissions (ITF, 2010; Lemp et al., 2011; Thompson, 2015). In short, our findings point to roads being made safer 
through freight consolidation in a smaller number of heavy trucks in the EU. However, this could obviously also result in other problems in the supply chain.

With respect to urban freight pick-up and delivery in the so-called "last mile", heavy truck traffic has to contend with greater restrictions due to the built form of major European medium size and large cities focusing on the city center, which results in dense traffic, parking problems and high pollution levels (Dablanc et al., 2013). Heavy and medium trucks are regarded as slow vehicles that may contribute significantly to traffic congestion and pollution in urban areas. In addition, local governments have implemented regulations that impose access restrictions based on truck weight and dimensions (Nuzzolo \& Comi, 2014).

This, together with the effect of liberalization processes in the European road haulage market during recent years, has resulted in greater numbers of light trucks than heavier trucks being involved in urban traffic, as they are apparently more efficient and, in certain cases, may be safer. This may be important for further research into the optimal dimension of freight transport vehicles with sustainability/safety/efficiency approaches, but is beyond the scope of the current article.

\section{ACKNOWLEDGEMENTS}

We would like to thank Prof. Jiuh-Biing Sheu, the anonymous Editorial Advisory Board member and both anonymous reviewers for their very helpful comments. The authors would also like to express their gratitude to the Dirección General de Tráfico (Spanish Road Traffic Directorate General) for the human and financial resources provided for this study (grant reference: SPIP20141274).

\section{REFERENCES}

Abdelwahab, H.T, Abdel-Aty, M. (2004). Investigating the effect of light truck vehicle percentages on head-on fatal traffic crashes. Journal of Transportation Engineering (ASCE), 130, 429-437.

Abdel-Aty, M., Abdelwahab, H. (2004). Analysis and prediction of traffic fatalities resulting from angle collisions including the effect of vehicles' configuration and compatibility. Accident Analysis and Prevention, 36, 457-469.

af Wåhlberg, A.E. (2008). Meta-analysis of the difference in accident risk between long and short truck configurations. Journal of Risk Research, 11, 315-333. 
Albalate, D. (2008). Lowering blood alcohol content levels to save lives: the European experience. Journal of Policy Analysis \& Management, 27, 20-39.

Albalate, D., Bel, G. (2012). Motorways tolls, and road safety: evidence from Europe. SERIES-Journal Spanish Economic Association, 3, 457-473.

Allen, J., Browne, M., Cherrett, T. (2012). Investigating relationships between road freight transport, facility location, logistics management and urban form. Journal of Transport Geography, 24, 45-57.

Anderson, M. (2008). Safety for whom? The effects of light trucks on traffic fatalities. Journal of Health Economics, 27, 973-989.

Anderson, M. L., Auffhammer, M. (2014). Pounds that kill: the external costs of vehicle weight. The Review of Economic Studies, 81, 535-571.

Bálint, A., Fagerlind, H., Martinsson, J., Holmqvist, K. (2013). Correlation between truck combination length and injury risk. In Australasian College of Road Safety Conference, November 2013, Adelaide, South Australia, Australia.

Bishai, D., Quresh, A., James, P., Ghaffar, A. (2006). National road casualties and economic development. Health Economics, 15, 65-81.

Blower, D., Green, P., Matteson, A. (2010). Condition of Trucks and Truck Crash Involvement. Transportation Research Record: Journal of the Transportation Research Board, 2194, 21-28.

Braver, E. R., Zador, P. L., Thum, D., Mitter, E. L., Baum, H. M., Vilardo, F. J. (1997). Tractor-trailer crashes in Indiana: A case-control study of the role of truck configuration. Accident Analysis and Prevention, 29, 79-96.

Braver, E. R., Trempel, R. E. (2004). Are older drivers actually at higher risk of involvement in collisions resulting in deaths or non-fatal injuries among their passengers and other road users? Injury Prevention, 10(1), 27-32.

Britto, R. A., Corsi, T. M., Grimm, C. M. (2010). The relationship between motor carrier financial performance and safety performance. Transportation Journal, 42-51.

Brozović, N., Ando, A. W. (2009). Defensive purchasing, the safety (dis) advantage of light trucks, and motor-vehicle policy effectiveness. Transportation Research Part B: Methodological, 43(5), 477-493.

Cantor, D. E., Corsi, T. M., Grimm, C. M. (2008). Determinants of motor carrier safety technology adoption. Transportation Research Part E: Logistics and Transportation Review, 44(5), 932-947.

Cantor, D. E., Corsi, T. M., Grimm, C. M. (2009). Do electronic logbooks contribute to motor carrier safety performance? Journal of Business Logistics, 30(1), 203-222.

Cantor, D.E., Corsi, T.M., Grimm, C.M., Özpolat, K. (2010). A driver focused truck crash prediction model. Transportation Research Part E: Logistics and Transport Reviews, 46, 683-692.

Cantor, D. E., Celebi, H., Corsi, T. M., Grimm, C. M. (2013). Do owner-operators pose a safety risk on the nation's highways? Transportation Research Part E: Logistics and Transportation Review, 59, 34-47. 
Carson, J. L. (2011). Directory of significant truck size and weight research. National Cooperative Highway Research Program. Texas Transportation Institute, Texas. Accessible at: http://transportationproductivity.org/templates/files/aashto-directoryof-significant-truck-size-weight-research.pdf.

Carsten, O. (1987). Safety implications of truck configuration. Transportation Research Record, 1111, 17-26.

Castillo-Manzano, J.I., Castro-Nuño, M. (2012). Driving licenses based on points systems: Efficient road safety strategy or latest fashion in global transport policy? A world wide meta-analysis. Transport Policy, 21, 191-201.

Castillo-Manzano, J. I., Castro-Nuño, M., Fageda, X. (2014). Can health public expenditure reduce the tragic consequences of road traffic accidents? The EU-27 experience. The European Journal of Health Economics, 15(6), 645-652.

Castillo-Manzano, J.I., Castro-Nuño, M., Fageda, X. (2015). Can cars and trucks coexist peacefully on highways? Analyzing the effectiveness of road safety policies in Europe. Accident Analysis and Prevention, 77, 120-126.

Chang, L. Y., Chien, J. T. (2013). Analysis of driver injury severity in truck-involved accidents using a non-parametric classification tree model. Safety Science, 51, 17-22.

Chang, L.Y., Mannering, F. (1999). Analysis of injury severity and vehicle occupancy in truck- and non-truck-involved accidents. Accident Analysis and Prevention, 31 (5), 579-592.

Choi, S., Oh, Ch., Kim, M. (2014). Risk Factors Related to Fatal Truck Crashes on Korean Freeways. Traffic Injury Prevention, 15, 73-80.

Corsi, T. M., Grimm, C. M., Cantor, D. E., Sienicki, D. (2012). Safety performance differences between unionized and non-union motor carriers. Transportation Research Part E: Logistics and Transportation Review, 48(4), 807-816.

Corsi, T. M., Grimm, C., Cantor, D., Wright, D. (2014). Should smaller commercial trucks be subject to safety regulations? Transportation Journal, 53(2), 117-142.

Dablanc, L., Giuliano, G., Holliday, K., O'Brien, T. (2013). Best practices in urban freight management: Lessons from an international survey. Transportation Research Record: Journal of the Transportation Research Board, 2379, 29-38.

Desapriya, E., Subzwari, S., Sasges, D., Basic, A., Alidina, A., Turcotte, K., Pike, I. (2010). Do light truck vehicles (LTV) impose greater risk of pedestrian injury than passenger cars? A meta-analysis and systematic review. Traffic injury prevention, 11(1), 48-56.

Dong, C., Clarke, D. B., Richards, S. H., Huang, B. (2014). Differences in passenger car and large truck involved crash frequencies at urban signalized intersections: An exploratory analysis. Accident Analysis and Prevention, 62, 87-94.

Elvik, R. (2012). Speed limits, enforcement and health consequences. Annual Review of Public Health, 33, 225-238.

Evans, L., Frick, M. (1993). Mass ratio and relative driver fatality risk in two-vehicle crashes. Accident Analysis and Prevention, 25 (2), 213-224. 
Evans, L., Frick, M. (1994). Car mass and fatality risk: has the relationship changed? American Journal of Public Health, 84 (1), 33-36.

Friswell, R., Williamson, A. (2013). Comparison of the fatigue experiences of short haul light and long distance heavy vehicle drivers. Safety Science, 57, 203-213.

Gayer, T. (2004). The fatality risks of sport-utility vehicles, vans, and pickups relative to cars. The Journal of Risk and Uncertainty 28 (2), 103-133.

Grimm, M., Treibich, C. (2013). Determinants of road traffic crash fatalities across Indian states. Health Economics, 22(8), 915-930.

Hall, R. W., Mukherjee, A. (2008). Bounds on effectiveness of driver hours-of-service regulations for freight motor carriers. Transportation Research Part E: Logistics and Transportation Review, 44(2), 298-312.

Harb, R., Radwan, E., Yan, X., Abdel-Aty, M. (2007). Light truck vehicles (LTVs) contribution to rear-end collisions. Accident Analysis \& Prevention, 39(5), 10261036.

Hauer, E. (2001). Computing and interpreting accident rates for vehicle types or driver groups. Transportation Research Record: Journal of the Transportation Research Board, 1746, 69-73.

Hickman, J.S., Hanowski, R.J. (2011). Use of a video monitoring approach to reduce atrisk driving behaviors in commercial vehicle operations. Transportation Research Part F, 14 (3), 189-198.

Holz-Rau, C., Scheiner, J., Sicks, K. (2014). Travel distances in daily travel and longdistance travel: what role is played by urban form? Environment and Planning A, 46(2), 488-507.

Huang, H., Chin, H. C., Haque, M. M. (2008). Severity of driver injury and vehicle damage in traffic crashes at intersections: a Bayesian hierarchical analysis. Accident Analysis \& Prevention, 40(1), 45-54.

Huang, H., Siddiqui, C., Abdel-Aty, M. (2011). Indexing crash worthiness and crash aggressivity by vehicle type. Accident Analysis and Prevention, 43, 1364-1370.

ITF (International Transport Forum) (2010). Moving freight with better trucks. OECD. Paris.

Jamroz, K., (2012). The impact of road network structure and mobility on the national traffic fatality rate. Procedia Social Behavior Science, 54, 1370-1377.

Jones, I.S., Stein, H.S., Zador, P. (1983): Influence of Truck Size and Weight on Highway Crashes. Research Note 105. Washington, DC: Insurance Institute for Highway Safety.

Kahane, C. J. (2003). Vehicle weight, fatality risk and crash compatibility of model year 1991-99 passenger cars and light trucks (No. HS-809 662). National Highway Traffic Safety Administration. Washington DC. Accessible at: http://www.nhtsa.dot.gov/cars/rules/regrev/evaluate/pdf/809662.pdf. 
Kanaroglou, P. S., Buliung, R. N. (2008). Estimating the contribution of commercial vehicle movement to mobile emissions in urban areas. Transportation Research Part E: Logistics and Transportation Review, 44(2), 260-276.

Khorashadi, A., Niemeier, D., Shankar, V., Mannering, F. (2005). Differences in rural and urban driver-injury severities in accidents involving large-trucks: an exploratory analysis. Accident Analysis \& Prevention, 37(5), 910-921.

Koliousis, I., Koliousis, P., Papadimitriou, S. (2013). Estimating the impact of road transport deregulation in short sea shipping: experience from deregulation in the European Union. International Journal of Shipping and Transport Logistics, 5, 500511.

Kopits, E., Cropper, M. (2005). Traffic fatalities and economic growth. Accident Analysis and Prevention, 37, 169-178.

Langford, J., Koppel, S. (2006). Epidemiology of older driver crashes-identifying older driver risk factors and exposure patterns. Transportation Research Part F: Traffic Psychology and Behaviour, 9(5), 309-321.

Lemp, J. D., Kockelman, K. M., Unnikrishnan, A. (2011). Analysis of large truck crash severity using heteroskedastic ordered probit models. Accident Analysis \& Prevention, 43(1), 370-380.

Levin, A., Lin, Ch.-F., Chu, Ch.-S.-J. (2002). Unit root tests in panel data: asymptotic and finite-sample properties. Journal of Econometrics, 108, 1-24.

Loeb, P.D., Clarke, W.A. (2007). The determinants of truck accidents. Transportation Research Part E: Logistics and Transportation Review, 43, 442-452.

Lyman, S., Braver, E. R. (2003). Occupant deaths in large truck crashes in the United States: 25 years of experience. Accident Analysis and Prevention, 35, 731-739.

McGwin Jr, G., Brown, D. B. (1999). Characteristics of traffic crashes among young, middle-aged, and older drivers. Accident Analysis and Prevention, 31, 181-198.

McKinnon, A.C. (2008). Should the maximum length and weight of trucks be increased? A review of European research. Logistics Research Centre, Heriot-Watt University, Edinburgh. In Proceedings of the 13th International Symposium on Logistics 6-8 July 2008, Bangkok.

Mejza, M. M., Corsi, T. M. (1999). Assessing motor carrier potential for improving safety processes. Transportation Journal, 36-50.

Mejza, M. C., Barnard, R. E., Corsi, T. M., Keane, T. (2003). Driver management practices of motor carriers with high compliance and safety performance. Transportation Journal, 16-29.

Milton, J. C., Shankar, V. N., Mannering, F. L. (2008). Highway accident severities and the mixed logit model: an exploratory empirical analysis. Accident Analysis and Prevention, 40, 260-266.

Mooren, L., Grzebieta, R., Williamson, A., Olivier, J., Friswell, R. (2014). Safety management for heavy vehicle transport: A review of the literature. Safety Science, $62,79-89$. 
Noland, R.B. (2003). Traffic fatalities and injuries: the effect of changes in infrastructure and other trends. Accident Analysis \& Prevention, 35, 599-611.

Nuzzolo, A., Comi, A. (2014). Urban freight demand forecasting: a mixed quantity/delivery/vehicle-based model. Transportation Research Part E: Logistics and Transportation Review, 65, 84-98.

Ortega, A., Vassallo, J.M., Guzmán, A.F., Pérez-Martínez, P.J. (2014). Are Longer and Heavier Vehicles (LHVs) Beneficial for Society? A Cost Benefit Analysis to Evaluate their Potential Implementation in Spain. Transport Reviews, 34, 150-168.

Ossiander, E.M., Koepsell, T.D., McKnight, B. (2014). Crash fatality and vehicle incompatibility in collisions between cars and light trucks or vans. Injury Prevention. (in press), doi:10.1136/injuryprev-2013-041146.

Park, L., Pierce, D. (2013). Large Truck Safety Trends. American Transportation Research Institute. Virginia. Accessible at: http://cabadvantage.com/files/ATRI\%20Large\%20Truck\%20Safety\%20Trends\%205 $\% 2013 \% 20$ FINAL.pdf

Pierce, D., Park, L. (2014). Analyzing Large Truck Safety Trends. In Transportation Research Board 93rd Annual Meeting. (No. 14-1025).

Qin, X., Wang, K., Cutler, C. E. (2013). Logistic Regression Models of the Safety of Large Trucks. Transportation Research Record: Journal of the Transportation Research Board, 2392, 1-10.

Rakauskas, M. E., Ward, N. J., Gerberich, S. G. (2009). Identification of differences between rural and urban safety cultures. Accident Analysis \& Prevention, 41(5), 931937.

Rogers, M., M., Weber, W. L. (2011). Evaluating CO2 emissions and fatalities tradeoffs in truck transport. International Journal of Physical Distribution \& Logistics Management, 41(8), 750-767.

Saifizul, A.A., Yamanaka, H., Karim, M.R. (2011). Empirical analysis of gross vehicle weight and free flow speed and consideration on its relation with differential speed limit. Accident Analysis and Prevention, 43, 1068-1073.

Sanches Rodrigues, V., Piecyk, M., Mason, R., Boenders, T. (2015). The longer and heavier vehicle debate: A review of empirical evidence from Germany. Transportation Research Part D: Transport and Environment, 40, 114-131.

Savage, I. (2011). A structural model of safety and safety regulation in the truckload trucking industry. Transportation Research Part E: Logistics and Transportation Review, 47(2), 249-262.

Steer J., Dionori, F., Casullo, L., Vollath, C., Frisoni, R., Carippo, F., Ranghetti, D. (2013). A review of mega trucks. Major issues and case studies. Directorate general for internal policies. Policy department b: structural and cohesion policies Transport and tourism. European Parliament's Committee on Transport and Tourism.

Stein, H. S., Jones, I. S. (1988). Crash involvement of large trucks by configuration: a case-control study. American Journal of Public Health, 78(5), 491-498. 
Thompson, R.G. (2015). Vehicle Orientated Initiatives for Improving the Environmental Performance of Urban Freight Systems. In Green Logistics and Transportation (pp. 119-129). Springer International Publishing.

TRB (Transportation Research Board). (1990). Truck Weight Limits: Issues and Options. Special Report 225. Washington D.C. Accessible at: http://pubsindex.trb.org/view.aspx?type=MO\&id=309190.

Vallette, G.R., McGee, H.W., Sanders, J.H., Enger, D.J. (1981). The Effect of Truck Size and Weight on Accident Experience and Traffic Operations, Volume 3: Accident Experience of Large Trucks. Federal Highway Administration Report No. FHWA-RD-80-137. Washington, D.C.

Volvo Trucks (2013). European Accident Research and Safety Report. Acccessible at: http://www.volvotrucks.com/SiteCollectionDocuments/VTC/Corporate/Values/ART \%20Report\%202013.pdf.

Welki, A. M., Zlatoper, T. J. (2009). How highway safety regulations and enforcement activities affect subcategories of motor vehicle fatalities. Transportation Research Part E: Logistics and Transportation Review, 45(6), 1030-1038.

White, M. (2004). The "Arms Race" on American roads: the effect of sport utility vehicles and pickup trucks on traffic safety. Journal of Law and Economics 47 (2), 333-355.

Yannis, G., Papadimitriou, E., Folla, K. (2014). Effect of GDP changes on road traffic fatalities. Safety Science, 63, 42-49.

Yee, W.Y., Cameron, P.A., Bailey, M.J. (2006). Road traffic injuries in the elderly. Emergency Medicine Journal 23, 42-6.

Zaloshnja, E., Miller, T. R. (2004). Costs of large truck-involved crashes in the United States. Accident Analysis and Prevention, 36, 801-808.

Zhu, X., Srinivasan, S. (2011). A comprehensive analysis of factors influencing the injury severity of large-truck crashes. Accident Analysis and Prevention, 43, 49-57.

Zwerling, C., Peek-Asa, C., Whitten, P. S., Choi, S. W., Sprince, N. L., Jones, M. P. (2005). Fatal motor vehicle crashes in rural and urban areas: decomposing rates into contributing factors. Injury Prevention, 11(1), 24-28. 
TABLES

TABLE 1. Variables used in the empirical analysis

\begin{tabular}{|c|c|c|c|}
\hline Variables & Description & Source & Type of data \\
\hline Fatalities per capita & $\begin{array}{c}\text { Number of traffic fatalities per } \\
\text { million inhabitants }\end{array}$ & $\begin{array}{c}\text { CARE (EU road accident } \\
\text { database) }\end{array}$ & Dependent variable \\
\hline $\begin{array}{l}\text { Accidents per } \\
\text { capita }\end{array}$ & $\begin{array}{l}\text { Number of traffic accidents per } \\
\text { million inhabitants }\end{array}$ & $\begin{array}{c}\text { CARE (EU road accident } \\
\text { database) }\end{array}$ & Dependent variable \\
\hline Motorization & $\begin{array}{l}\text { Number of registered passenger cars } \\
\text { per thousand inhabitants }\end{array}$ & $\begin{array}{l}\text { UNECE, EUROSTAT } \\
\text { (for population) }\end{array}$ & Country attribute \\
\hline GDP per capita & $\begin{array}{l}\text { Per capita gross domestic product in } \\
\text { International Comparable Prices } \\
\text { (US\$ at } 2005 \text { prices and PPP) }\end{array}$ & EUROSTAT & Country attribute \\
\hline Motorway density & $\begin{array}{c}\text { Number kms of motorways divided } \\
\text { by km } \text { kf the country }^{2} \text { of }\end{array}$ & UNECE, EUROSTAT & Country attribute \\
\hline Other roads density & $\begin{array}{l}\text { Number kms of other roads (state, } \\
\text { provincial and district) divided by } \\
\text { country } \mathrm{km}^{2}\end{array}$ & UNECE, EUROSTAT & Country attribute \\
\hline Old & $\%$ population aged $60+$ & EUROSTAT & Country attribute \\
\hline Young & $\%$ population aged $15-24$ & EUROSTAT & Country attribute \\
\hline Population density & Density of population & EUROSTAT & Country attribute \\
\hline Trucks_light & $\begin{array}{l}\text { Number of trucks (trucks }+ \text { semi- } \\
\text { trailers with load capacity }<5000 \mathrm{~kg} \text { ) } \\
\text { per million inhabitants }\end{array}$ & EUROSTAT & Trucks \\
\hline Trucks_medium & $\begin{array}{l}\text { Number of trucks (trucks + semi- } \\
\text { trailers with load capacity } 5000 \mathrm{~kg}- \\
14999 \mathrm{~kg} \text { ) per million inhabitants }\end{array}$ & EUROSTAT & Trucks \\
\hline Trucks_heavy & $\begin{array}{l}\text { Number of trucks (trucks }+ \text { semi- } \\
\text { trailers with load capacity } \geq 15000 \\
\mathrm{~kg} \text { ) per million inhabitants }\end{array}$ & EUROSTAT & Trucks \\
\hline BAC_05 & $\begin{array}{c}\text { Dummy variables that take a value of } \\
1 \text { if the permitted maximum BAC } \\
\text { rate is under } 0.5 \mathrm{~g} / 1\end{array}$ & $\begin{array}{l}\text { European Commission } \\
\text { Road Safety Website }\end{array}$ & Road safety policy \\
\hline Points_system & $\begin{array}{l}\text { Dummy variable that takes a value of } \\
1 \text { if a points driving license system is } \\
\text { in force }\end{array}$ & $\begin{array}{c}\text { European Transport } \\
\text { Safety Council (ETSC) }\end{array}$ & Road safety policy \\
\hline Speed limits & Maximum speed limits & $\begin{array}{l}\text { European Commission } \\
\text { Road Safety Website }\end{array}$ & Road safety policy \\
\hline
\end{tabular}


TABLE 2. Descriptive statistics of the variables used in the empirical analysis

\begin{tabular}{|c|c|c|c|c|c|}
\hline Variables & Mean & $\begin{array}{c}\text { Standard } \\
\text { Deviation }\end{array}$ & $\begin{array}{c}\text { Minimum } \\
\text { value }\end{array}$ & $\begin{array}{c}\text { Maximum } \\
\text { value }\end{array}$ & $\begin{array}{c}\text { Number of } \\
\text { observations }\end{array}$ \\
\hline Fatalities per capita & 103.46 & 45.26 & 21 & 257 & 379 \\
\hline Accidents per capita & 42798.45 & 77732.46 & 633.9 & 395689 & 379 \\
\hline Motorization & 430.54 & 111.61 & 134 & 686 & 388 \\
\hline GDP per capita & 25331.75 & 11622.87 & 6737 & 74128 & 391 \\
\hline Motorway density & 1.73 & 1.74 & 0 & 6.35 & 388 \\
\hline Other roads density & 129.09 & 134.09 & 0.49 & 979.87 & 388 \\
\hline Old & 21.00 & 2.64 & 15.1 & 27.1 & 389 \\
\hline Young & 13.22 & 1.65 & 10 & 17.2 & 392 \\
\hline Population density & 0.16 & 0.23 & 0.02 & 1.37 & 392 \\
\hline Trucks_light & 52007.98 & 32449.33 & 2396.3 & 159826 & 231 \\
\hline Trucks_medium & 5472.032 & 2540.95 & 1297 & 17100 & 231 \\
\hline Trucks_heavy & 4140.57 & 2596.62 & 31 & 11395 & 231 \\
\hline BAC_05 & 0.28 & 0.45 & 0 & 1 & 392 \\
\hline Points_system & 0.60 & 0.49 & 0 & 1 & 392 \\
\hline Speed limits & 121.5 & 13.51 & 80 & 112 & 392 \\
\hline
\end{tabular}


TABLE 3. Correlation matrix of the variables used in the empirical analysis

\begin{tabular}{|c|c|c|c|c|c|c|c|c|c|c|c|c|c|c|c|}
\hline Variables & Fatal. & Acc. & Motor. & GDP & M_Den & $\begin{array}{c}\text { Other } \\
\text { Den }\end{array}$ & Old & Young & Trucks_sml & Trucks_med & Trucks_lge & P_Dens & BAC & Points & Speed \\
\hline Fatalities per capita & 1 & & & & & & & & & & & & & & \\
\hline Accidents per capita & -0.05 & 1 & & & & & & & & & & & & & \\
\hline GDP per capita & -0.45 & 0.03 & 0.77 & 1 & & & & & & & & & & & \\
\hline Motorway density & -0.32 & 0.08 & 0.53 & 0.68 & 1 & & & & & & & & & & \\
\hline Other roads density & -0.20 & -0.06 & 0.10 & -0.01 & 0.10 & 1 & & & & & & & & & \\
\hline Old & -0.36 & 0.36 & 0.23 & -0.02 & -0.16 & -0.12 & 1 & & & & & & & & \\
\hline Trucks_light & -0.21 & 0.08 & 0.27 & 0.17 & 0.21 & -0.07 & -0.32 & 0.02 & 1 & & & & & & \\
\hline Trucks_medium & 0.42 & -0.20 & -0.03 & -0.17 & -0.39 & 0.29 & -0.09 & 0.03 & -0.16 & 1 & & & & & \\
\hline Trucks_heavy & -0.18 & -0.31 & 0.33 & 0.51 & 0.30 & 0.27 & -0.06 & -0.12 & -0.01 & 0.17 & 1 & & & & \\
\hline Population density & -0.36 & 0.04 & 0.13 & 0.10 & 0.16 & 0.79 & -0.07 & -0.02 & 0.17 & 0.24 & 0.23 & 1 & & & \\
\hline BAC_05 & 0.01 & -0.02 & 0.01 & -0.06 & -0.19 & -0.09 & 0.18 & -0.02 & -0.08 & 0.15 & 0.11 & -0.25 & 1 & & \\
\hline Points_system & -0.05 & 0.13 & 0.23 & 0.04 & 0.31 & 0.08 & 0.05 & -0.09 & 0.15 & -0.23 & 0.18 & -0.31 & -0.02 & 1 & \\
\hline Speed limits & 0.14 & 0.27 & 0.11 & 0.21 & -0.20 & $\begin{array}{l}-0.14 \\
\end{array}$ & 0.04 & -0.05 & -0.38 & -0.31 & -0.03 & -0.32 & -0.02 & 0.17 & 1 \\
\hline
\end{tabular}

CORRELATION GDP -MOTORISATION -EXCLUDE MOTORISATION CORRELATION DENSITY POPULATION - OTHER ROADS DENSITY - EXCLUDE OTHER ORADS DENSITY 
TABLE 4. Variance inflation factors of the variables used in the empirical analysis

\begin{tabular}{|c|c|c|}
\hline Variables & Fatalities per capita & Accidents per capita \\
\hline Motorization & 4.60 & 4.63 \\
\hline GDP per capita & 6.70 & 6.54 \\
\hline Motorway density & 3.51 & 3.22 \\
\hline Other roads density & 7.91 & 7.74 \\
\hline Old & 4.51 & 4.62 \\
\hline Young & 4.72 & 4.94 \\
\hline Population density & 8.73 & 8.48 \\
\hline Trucks_light & 2.58 & 2.47 \\
\hline Trucks_medium & 2.12 & 2.14 \\
\hline Trucks_heavy & 1.97 & 1.89 \\
\hline BAC_05 & 1.32 & 1.31 \\
\hline Points_system & 1.71 & 1.59 \\
\hline Speed limits & 2.14 & 2.10 \\
\hline
\end{tabular}


TABLE 5. Results of estimates (OLS model)

\begin{tabular}{|c|c|c|c|c|}
\hline \multirow[t]{2}{*}{ Independent variables } & \multicolumn{4}{|c|}{ Dependent variable: Number of traffic fatalities per capita } \\
\hline & $(\mathbf{1})$ & (2) & (3) & $(4)$ \\
\hline $\begin{array}{l}\text { Number of traffic fatalities per } \\
\text { capita (lagged) }\end{array}$ & - & $0.43 * * *(0.11)$ & - & - \\
\hline Motorization & $0.00037(0.0005)$ & $-0.00021(0.00044)$ & $0.0009(0.0007)$ & $0.00012(0.0006)$ \\
\hline GDP per capita & $0.000039 * * *(0.000013)$ & $0.000024 * * *(9.31 \mathrm{e}-06)$ & $0.000047 * * *(0.000013)$ & $0.000046 * * *(0.000013)$ \\
\hline GDP per capita $^{2}$ & $-2.48 \mathrm{e}-10 * * *(1.48 \mathrm{e}-10)$ & $-1.90 \mathrm{e}-10 *(9.89 \mathrm{e}-11)$ & $-9.37 \mathrm{e}-10 * * *(2.78 \mathrm{e}-10)$ & $-3.60 \mathrm{e}-10 * *(1.58 \mathrm{e}-10)$ \\
\hline Motorway density & $-0.003(0.06)$ & $-0.008(0.05)$ & $-0.06(0.08)$ & $-0.01(0.06)$ \\
\hline Density of other roads & $0.002 * * *(0.006)$ & $0.0022 * * *(0.0007)$ & $0.0029 * * *(0.0005)$ & $0.002 * * *(0.0005)$ \\
\hline Old & $0.03(0.02)$ & $0.03 *(0.017)$ & $0.06(0.03)$ & $0.02(0.02)$ \\
\hline Young & $0.04 * *(0.02)$ & $0.03 *(0.018)$ & $0.03(0.02)$ & $0.03 *(0.01)$ \\
\hline Population density & $-1.99 * * *(0.53)$ & $-1.88 * * *(0.55)$ & $-2.27 * * *(0.59)$ & $-1.96 * * *(0.53)$ \\
\hline Trucks_light & $1.63 \mathrm{e}-06(1.55 \mathrm{e}-06)$ & $-6.61 \mathrm{e}-08(1.14 \mathrm{e}-06)$ & $1.64 \mathrm{e}-06(1.87 \mathrm{e}-06)$ & $2.49 \mathrm{e}-06(2.20 \mathrm{e}-06)$ \\
\hline Trucks_medium & $0.000026 * * *(8.38 \mathrm{e}-06)$ & $0.000021 * * *(3.62 \mathrm{e}-06)$ & $0.000022 * *(9.00 \mathrm{e}-06)$ & $0.000026 * * *(8.48 \mathrm{e}-06)$ \\
\hline Trucks_heavy & $-0.000015(0.000012)$ & $3.35 \mathrm{e}-07(5.35 \mathrm{e}-06)$ & $-9.20 \mathrm{e}-06(0.000011)$ & $-9.48 \mathrm{e}-06(0.000011)$ \\
\hline BAC_05 & $0.023(0.07)$ & $-0.0017(0.05)$ & $0.004(0.07)$ & $0.006(0.06)$ \\
\hline Points_system & $0.00006(0.04)$ & $-0.03(0.03)$ & $0.02(0.04)$ & $0.004(0.04)$ \\
\hline Speed limits & $0.04 * * *(0.01)$ & $0.014(0.010)$ & $0.04 * * *(0.01)$ & $0.04 * * *(0.01)$ \\
\hline Motorization x GDP per capita & - & - & $1.27 \mathrm{e}-07 * * *(4.81 \mathrm{e}-08)$ & - \\
\hline $\begin{array}{c}\text { Motorization x Trucks per } \\
\text { capita } \\
\end{array}$ & - & - & - & $1.25 \mathrm{e}-08 * *(4.97 \mathrm{e}-09)$ \\
\hline Time_trend & $-0.09 * * *(0.012)$ & $-0.056 * * *(0.010)$ & $-0.09 * * *(0.011)$ & $-0.09 * * *(0.011)$ \\
\hline Intercept & $-0.03(1.75)$ & $0.64(1.33)$ & $1.08(2.15)$ & $-0.36(2.03)$ \\
\hline Country fixed effects & YES & YES & YES & YES \\
\hline $\mathrm{R}^{2}$ & 0.96 & 0.96 & 0.96 & 0.96 \\
\hline Test joint sign (Wald $\chi^{2}$ ) & $100.58 * * *$ & $120.69 * * *$ & $104.84 * * *$ & $100.63 * * *$ \\
\hline $\begin{array}{c}\text { Ramsey Reset Test (Ho: No } \\
\text { omitted variables) }\end{array}$ & 1.21 & 0.22 & 1.83 & 0.23 \\
\hline Breusch-Pagan/Cook- & & & & \\
\hline
\end{tabular}




\begin{tabular}{|c|c|c|c|}
\hline $\begin{array}{c}\text { Weisberg test for } \\
\text { heteroscedasticity (Ho: } \\
\text { Constant variance) }\end{array}$ & $7.96^{* * *}$ & $6.79 * * *$ & $8.10^{* * *}$ \\
\hline $\begin{array}{c}\text { Wooldridge test }- \\
\text { autocorrelation } \\
\text { (Ho: First-order } \\
\text { autocorrelation) }\end{array}$ & & & $6.03 * * *$ \\
\hline $\begin{array}{c}\text { Test: }- \text { Trucks_light }+ \\
\text { Trucks_heavy = }\end{array}$ & $4.88^{* *}$ & $6.02^{* *}$ & $5.49^{* *}$ \\
\hline Number of observations & 1.67 & $10.98^{* *}$ & $3.08^{*}$ \\
\hline
\end{tabular}

Note 1: Standard errors are given in brackets. Robust to heteroscedasticity and clustered by country.

Note 2: Statistical significance at $1 \%(* * *), 5 \%(* *), 10 \%(*)$.

TABLE 6. Results of estimates (Population-averaged panel-data model with a negative binomial distribution)

\begin{tabular}{|c|c|c|c|c|}
\hline \multirow[t]{2}{*}{ Independent variables } & \multicolumn{4}{|c|}{ Dependent variable: Number of traffic fatalities } \\
\hline & (1) & $(2)$ & (3) & (4) \\
\hline $\begin{array}{l}\text { Number of traffic } \\
\text { fatalities (lagged) }\end{array}$ & - & $0.33 * * *(0.10)$ & - & - \\
\hline Motorization & $0.00020(0.0004)$ & $-0.00012(0.0004)$ & $0.001 *(0.0005)$ & $0.00012(0.00046)$ \\
\hline GDP per capita & $0.000043 * * *(9.19 \mathrm{e}-06)$ & $0.000028 * * *(8.75 \mathrm{e}-06)$ & $0.000051 * * *(8.98 \mathrm{e}-06)$ & $0.000048 * * *(9.23 \mathrm{e}-06)$ \\
\hline GDP per capita $^{2}$ & $-2.80 \mathrm{e}-10 * * *(1.26 \mathrm{e}-10)$ & $-2.52 \mathrm{e}-10 * * *(1.00 \mathrm{e}-10)$ & $-1.02 \mathrm{e}-09 * * *(2.24 \mathrm{e}-10)$ & $-3.60 \mathrm{e}-10 * * *(1.19 \mathrm{e}-10)$ \\
\hline Motorway density & $-0.02(0.05)$ & $-0.003(0.05)$ & $-0.08(0.06)$ & $-0.021(0.05)$ \\
\hline Density of other roads & $0.0027 * * *(0.0004)$ & $0.002 * * *(0.0006)$ & $0.003 * * *(0.0004)$ & $0.002 * * *(0.00043)$ \\
\hline Old & $0.21(0.17)$ & $0.03 *(0.017)$ & $-0.005(0.015)$ & $0.019(0.016)$ \\
\hline Young & $0.04 * * *(0.01)$ & $0.04 * * *(0.016)$ & $0.023 *(0.0014)$ & $0.035 * * *(0.011)$ \\
\hline Trucks_light & $5.16 \mathrm{e}-07(1.44 \mathrm{e}-06)$ & $-1.17 \mathrm{e}-07(1.15 \mathrm{e}-06)$ & $5.15 \mathrm{e}-07(1.70 \mathrm{e}-06)$ & $9.53 \mathrm{e}-07(1.98 \mathrm{e}-06)$ \\
\hline Trucks_medium & $0.000022 * * *(6.54 \mathrm{e}-06)$ & $0.000022 * * *(3.15 \mathrm{e}-06)$ & $0.000019 * * *(5.68 \mathrm{e}-06)$ & $0.000022 * * *(6.22 \mathrm{e}-06)$ \\
\hline Trucks_heavy & $-7.95 \mathrm{e}-06(8.40 \mathrm{e}-06)$ & $-1.39 \mathrm{e}-06^{*}(4.56 \mathrm{e}-06)$ & $-4.75 \mathrm{e}-06(6.90 \mathrm{e}-06)$ & $-5.95 \mathrm{e}-06(7.20 \mathrm{e}-06)$ \\
\hline Population density & $-2.18 * * *(0.42)$ & $-2.02 * * *(0.46)$ & $-2.50 * * *(0.46)$ & $-2.15 * * *(0.43)$ \\
\hline
\end{tabular}




\begin{tabular}{|c|c|c|c|c|}
\hline BAC_05 & $0.013(0.05)$ & $-0.001(0.04)$ & $-0.01(0.05)$ & $0.001(0.05)$ \\
\hline Points_system & $0.011(0.03)$ & $-0.019(0.026)$ & $0.029(0.03)$ & $0.014(0.035)$ \\
\hline Speed limits & $0.03 * * *(0.009)$ & $0.02 * *(0.01)$ & $0.03 * * *(0.01)$ & $0.03 * * *(0.010)$ \\
\hline $\begin{array}{c}\text { Motorization x GDP per } \\
\text { capita }\end{array}$ & - & - & $1.49 \mathrm{e}-07 * * *(4.01 \mathrm{e}-08)$ & - \\
\hline $\begin{array}{l}\text { Motorization x Trucks per } \\
\text { capita }\end{array}$ & - & - & - & $1.20 \mathrm{e}-08 * *(5.38 \mathrm{e}-09)$ \\
\hline Time_trend & $-0.08 * * *(0.009)$ & $-0.06 * * *(0.01)$ & $-0.09 * * *(0.009)$ & $-0.09 * * *(0.009)$ \\
\hline Intercept & $0.74(1.26)$ & $0.51 * * *(1.23)$ & $2.15(1.61)$ & $0.59(1.47)$ \\
\hline Country fixed effects & YES & YES & YES & YES \\
\hline Test joint sign (Wald $\chi^{2}$ ) & $46.12 * * *$ & $51.34 * * *$ & $45.65 * *$ & $44.26 * *$ \\
\hline $\begin{array}{c}\text { Test: }- \text { Trucks_light }+ \\
\text { Trucks_heavy }=0\end{array}$ & $5.62 * *$ & $17.43 * * *$ & $5.12 * *$ & $6.58 * *$ \\
\hline Number of observations & 222 & 222 & 222 & 222 \\
\hline
\end{tabular}

Note 1: Standard errors are given in brackets (robust to heteroscedasticity). Regressions specify an AR(1) within-group correlation structure for the panels. Population is used as exposure variable. Note 2: Statistical significance at $1 \%(* * *), 5 \%(* *), 10 \%(*)$.

TABLE 7. Results of estimates (Accidents per capita)

\begin{tabular}{|c|c|c|c|c|c|c|}
\hline \multirow[t]{3}{*}{ Independent variables } & \multicolumn{6}{|c|}{ Dependent variable: Accidents per capita } \\
\hline & \multicolumn{3}{|c|}{ OLS } & \multicolumn{3}{|c|}{$\begin{array}{c}\text { Population-averaged panel-data model with a negative } \\
\text { binomial distribution }\end{array}$} \\
\hline & (1) & (2) & (3) & (1) & $(2)$ & (3) \\
\hline $\begin{array}{c}\text { Number accidents } \\
\text { (lagged) }\end{array}$ & - & $0.55 * * *(0.09)$ & - & - & $0.51 * * *(0.05)$ & - \\
\hline Motorization & $-0.0006(0.002)$ & $-0.002(0.002)$ & $-0.001(0.002)$ & $-0.00014(0.0017)$ & $-0.0019(0.0016)$ & $-0.0002(0.0018)$ \\
\hline GDP per capita & $0.00011 * *(0.00005)$ & $0.00004(0.00003)$ & $\begin{array}{c}0.00014 * * \\
(0.00006) \\
\end{array}$ & $\begin{array}{c}5.96 \mathrm{e}-06 \\
(0.000022) \\
\end{array}$ & $5.17 \mathrm{e}-06(0.00002)$ & $\begin{array}{c}0.000013 \\
(0.000026) \\
\end{array}$ \\
\hline GDP per capita ${ }^{2}$ & $\begin{array}{c}-1.38 \mathrm{e}-09 * * *(4.99 \mathrm{e}- \\
10) \\
\end{array}$ & $-7.80 \mathrm{e}-10(3.73 \mathrm{e}-10)$ & $\begin{array}{c}-1.89 \mathrm{e}-09 * \\
(7.69 \mathrm{e}-10)\end{array}$ & $\begin{array}{l}-5.98 \mathrm{e}-10 \\
(3.97 \mathrm{e}-10)\end{array}$ & $\begin{array}{c}-5.95 \mathrm{e}-10 *(3.27 \mathrm{e}- \\
10) \\
\end{array}$ & $\begin{array}{c}-7.02 \mathrm{e}-10(4.68 \mathrm{e}- \\
10)\end{array}$ \\
\hline Motorway density & $0.13(0.29)$ & $0.043(0.29)$ & $0.14(0.28)$ & $-0.04(0.22)$ & $-0.07(0.22)$ & $-0.03(0.22)$ \\
\hline Density of other roads & $0.001(0.0023)$ & $0.00043(0.0018)$ & $0.002(0.002)$ & $-0.002(0.002)$ & $-0.002(0.002)$ & $-0.002(0.002)$ \\
\hline
\end{tabular}




\begin{tabular}{|c|c|c|c|c|c|c|}
\hline Old & $-0.26(0.16)$ & $-0.30 *(0.15)$ & $-0.28 *(0.16)$ & $-0.21 *(0.13)$ & $-0.30 * * *(0.12)$ & $-0.21(0.13)$ \\
\hline Young & $0.33 * * *(0.08)$ & $0.26 * * *(0.09)$ & $0.29 * * *(0.08)$ & $0.30 * * *(0.07)$ & $0.20 * * *(0.07)$ & $0.29 * * *(0.008)$ \\
\hline Trucks_light & $0.000027 *(0.000013)$ & $\begin{array}{c}0.000029 * * \\
(0.000010)\end{array}$ & $\begin{array}{c}0.000030^{* *} \\
(0.000013) \\
\end{array}$ & $\begin{array}{c}0.000032 * * * \\
(0.000011) \\
\end{array}$ & $\begin{array}{c}0.000033 * * *(9.11 \mathrm{e}- \\
06)\end{array}$ & $\begin{array}{c}0.000033 * * * \\
(0.000011)\end{array}$ \\
\hline Trucks_medium & $-2.21 e-06(0.000043)$ & $-0.000014(0.000041)$ & $\begin{array}{c}-3.66 \mathrm{e}-06 \\
(0.000043)\end{array}$ & $\begin{array}{c}-4.87 \mathrm{e}-06 \\
(0.000022)\end{array}$ & $\begin{array}{l}-0.000015 \\
(0.000026)\end{array}$ & $\begin{array}{c}-4.58 \mathrm{e}-06 \\
(0.000022)\end{array}$ \\
\hline Trucks_heavy & $-0.00011 *(0.00008)$ & $-0.000099(0.00008)$ & $\begin{array}{l}-0.000081 \\
(0.000085) \\
\end{array}$ & $\begin{array}{l}-0.000098^{*} \\
(0.000053) \\
\end{array}$ & $\begin{array}{c}-0.00012 * * \\
(0.00005) \\
\end{array}$ & $\begin{array}{c}-0.000094 * \\
(0.000054) \\
\end{array}$ \\
\hline Population density & $6.83 * * *(2.45)$ & $6.55 * *(2.09)$ & $7.10 * * *(2.38)$ & $8.64 * * *(1.92)$ & $8.70 * * *(1.70)$ & $8.68 * * *(1.99)$ \\
\hline BAC_05 & $-0.14(0.24)$ & $-0.12(0.20)$ & $-0.21(0.24)$ & $-0.003(0.10)$ & $-0.001(0.11)$ & $-0.01(0.10)$ \\
\hline Points_system & $-0.02(0.22)$ & $-0.007(0.21)$ & $-0.01(0.22)$ & $0.06(0.13)$ & $0.07(0.14)$ & $0.06(0.13)$ \\
\hline Speed limits & $0.29 * * *(0.07)$ & $0.22 * *(0.05)$ & $0.31 * * *(0.08)$ & $0.24 * * *(0.05)$ & $0.21 * * *(0.04)$ & $0.24 * * *(0.05)$ \\
\hline $\begin{array}{c}\text { Motorization x Trucks } \\
\text { per capita } \\
\end{array}$ & 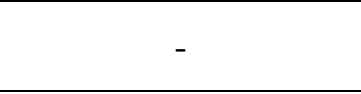 & - & $\begin{array}{c}5.58 \mathrm{e}-08(4.50 \mathrm{e}- \\
08)\end{array}$ & - & - & $\begin{array}{c}1.56 \mathrm{e}-08(2.83 \mathrm{e}- \\
08)\end{array}$ \\
\hline Time_trend & $-0.05(0.06)$ & $0.04(0.04)$ & $-0.08(0.06)$ & $-0.00004 * * *(0.03)$ & $0.07 * *(0.03)$ & $-0.006(0.04)$ \\
\hline Intercept & $-26.79 * * *(8.14)$ & $-19.09 * * *(5.91)$ & $-26.46 * * *(8.41)$ & $-23.16 * * *(5.76)$ & $-19.99 * * *(4.54)$ & $-23.44 * * *(5.87)$ \\
\hline Country fixed effects & YES & YES & YES & YES & YES & YES \\
\hline Test joint sign (Wald $\chi^{2}$ ) & $29.11 * * *$ & $37.18 * * *$ & $28.75 * * *$ & $185.36 * * *$ & $101.49 * * *$ & $94.55 * * *$ \\
\hline $\mathrm{R}^{2}$ & 0.86 & 0.90 & 0.86 & - & - & - \\
\hline $\begin{array}{c}\text { Ramsey Reset Test (Ho: } \\
\text { No omitted variables) }\end{array}$ & 1.86 & 1.40 & 1.61 & - & - & - \\
\hline $\begin{array}{l}\text { Breusch-Pagan/Cook- } \\
\text { Weisberg test for } \\
\text { heteroscedasticity (Ho: } \\
\text { Constant variance) }\end{array}$ & $7.17 * * *$ & $9.23 * * *$ & $4.69 * *$ & - & - & - \\
\hline $\begin{array}{l}\text { Wooldridge test - } \\
\text { autocorrelation } \\
\text { (Ho: First-order } \\
\text { autocorrelation) }\end{array}$ & $88.04 * * *$ & $90.05 * * *$ & $86.16^{* * *}$ & - & - & - \\
\hline $\begin{array}{l}\text { Test: }- \text { Trucks_medium } \\
\quad+\text { Trucks_heavy }=0\end{array}$ & 1.74 & 1.13 & 1.05 & $4.17 * *$ & $3.36^{*}$ & $3.98 * *$ \\
\hline Number of observations & 222 & 222 & 222 & 222 & 222 & 222 \\
\hline
\end{tabular}


Note 1: Standard errors are given in brackets (robust to heteroscedasticity). Regressions specify an AR(1) within-group correlation structure for the panels. Population is used as exposure variable in the regressions that use negative binomial distribution.

Note 2: Statistical significance at 1\%(***), 5\% (**), $10 \%(*)$. 